\title{
MAX WEBER Y LA POLFTICA DE PODER
}

\author{
Raymond Aron
}

Raymond Aron acomete en este texto un repaso crítico de las concepciones nacionales e imperiales de Max Webet, presentándolas como tipicas de su época y de su generación, moderadas en su propósito y concisas en su formulación. Emerge de ellas, según Aton, la figura de la traición que Weber se hizo a sí mismo en su teoría de la política, al escoger como valor postrero el poder del Estado nacional cuando «jamás el poder ha sido su dios».

Esta opción errónea de Weber se fundamenta para Aron en la oposición extrema planteada entre la ética de la convicción y la ética de la responsabilidad. Aron presenta a un Weber complejo estimulado por influencias darwinistas, nietzscheanas, económicas, nacionalistas y, paradójicamente, marxistas. 
La comunicación que me han encargado presentar, ${ }^{\ddagger}$ me ha planteado un problema de conciencia $o$, atreviéndome a utilizar ya el lenguaje de Weber, un problema de ciencia, así como también de política. Max Weber, sabido es, no fue tan sólo el sociólogo, el filósofo que todos admiramos; fue un pensador político, un publicista, quiso ser, en repetidas $\propto$ casiones, un político; y si, finalmente, no llegó a cruzar el umbral de la acción propiamente dicha, to es menos cierto que durante toda su vida fue amigo, consejero, inspirador de políticos involucrados en la acción cotidiana (Friedrich Naumann, ${ }^{2}$ por ejemplo). Así pues, no podré evocar, comentar o discutir determinadas ideas, determinadas tomas de posición de Max We. ber sin sugerir, por no decir formular, juicios sobre la Alemania wilhelminiara o, incluso, sobre el nacionalismo alemán de aquella época.

En otros tiempos, un francés hubiese podido y, quizás, hubiese debido negarse a redactar semejante informe, al sentirse tan temeroso de pecar de falta de tacto al hablar con toda franqueza, como de pecar de falta de franqueza al intentar no herir ninguna clase de susceptibilidad. Por lo que a mí respecta, no me ba parecido que las consideraciones de tipo nacional tuviesen que imponetse a mí, en un año como éste y en semejante circunstancia.

Por descontado, Max Weber no pertenece a un pasado definitivamente enterrado. Las controversias suscitadas por el libro de Wolfgang Momm. sen, Max Weber und die deutsche Politik, no caen dentro de la competer. cia de la ciencia pura. Conciernen tambiér al sentido que damos hoy en día a la Alemania wilhelminiana, a la Primera Guerra Mundial, a Ia República de Weimar y, por ende, a Hitler y a la Segunda Guerra Mundial: Max Weber, en su calidad de Machpolititer, pertenece, pues, a un pasado cuya interpretación influye sobre la conciencia que tenemos de la coyun-

1. Este texto fue escrito por Raymond Aron para el XV Congreso de los soció logos alemanes, de Heidelbetg, y publicado en Preuves, núm. 165 (noviembre de 1964). N. del $E$

2. Friedrioh Naumann: simpatizante político de Eduard Bernstein; reformista. 
tura actual. En este sentido, la intervención de un francés en la discusión podría parecer indiscreta si no fuese porque tres buenas razones viniesen a contrarrestar las posibles objeciones.

En primer lugar no se me puede tachar de hostilidad personal para con Weber, incluso si hoy por hoy ya no me expresase exactamente en los mismos términos que hace treinta años en la Sociologie allemande contemporaine. En segundo lugar, algunos de los problemas planteados por Weber cobran en la Francia de hoy día una actualidad sorprendente. Wolfgang Mommsen no anda desencaminado al señalar la similitud existente entre la Constitución de la V República francesa y las ideas constitucionales de Max Weber. Finalmente - y esta razón es decisiva- la comunidad europea se ha convertido hasta tal extremo en nuestra experiencia común, que la reflexión sobre el nacionalismo (o los nacionalismos de ayer) y sobre la Machtpolitik es tarea de todos nosotros, sociólogos y ciudadanos. No olvidaré por ello la distinción weberiana entre la ciencia y la política. Ahora bien, la forma en que el propio Weber practicaba dicha distinción no siempre era eỉemplar. Bueno será no confundir los hechos con los valores, la realidad con nuestros deseos. Así y todo, conviene tener cuidado en contemplar el mundo tal como es y no tal como quisiéramos que fuese o tal como nos tememos que sea -. Ia deformación pesimista, inspirada por el afán de demostrar como siendo inevitable e imprescindible una política de poder, no es menos de temer que la deformación idealista.

¿Qué es lo que vamos a llamar, en este artículo, política de poder o Machtpolitik o powerpolitics? Dos definiciones, rigurosa una, amplia la otra, pueden ser propuestas, me parece a mí. O bien llamamos Macbtpolitik a la política tal como se desarrolla entre los Estados, política sometida a la competencia de poder por no estar subordinada a ninguna ley, a ningún tribunal, a ninguna autoridad supranacional. En este sentido, toda política exterior ha sido, hasta nuestra época inclusive, política de poder, por muy diversas que hayan sido las modalidades de las unidades políticas y de las relaciones entre dichas unidades. O bien llamamos Machtpolitik a toda política, incluso en el seno de los Estados, que tiene por objetivo $y(o)$ como medio principal el poder. En este segundo sentido, cualquier política es, al menos parcialmente, política de poder. La política parece tanto más política de poder cuanto más se hace hincapié, en el análisis, en la dominación (Herrschaft) y en la lucha (Kampt).

Tanto si nos atenemos a la primera como a la segunda definición, Max Weber es, tanto como político (Politiker) como sociólogo, un típico Macbtpolitiker. Pertenece a la posteridad de Maquiavelo al propio tiem- 
po que a los contemporáneos de Nietzsche. Hubiese desechado, en tanto que desprovisto de significado, el interrogante antiguo: ¿cuál es el mejor régimen? La lucha entre las clases y los individuos por el poder (Macht - Herrschaft) se le antojaba la esencia misma o, si se prefiere, la base constante de la política. Según él, un pueblo o una persona sin ansia de poder se salía, por ese mismo motivo, de la política. Desde su punto de vista, las instituciones liberales y parlamentarias se convertían en las con. diciones necesarias para el desempeño de un papel mundial por parte de la nación. Las recomendaba a veces con el fin de que diesen la prueba fehaciente de que un pueblo, el pueblo alemán, estaba capacitado para desempeñat un papel mundial. Escribia:

«Tan sólo los pueblos superiores poseen vocación para impulsar el desarrollo del mundo. Si en alguna ocasión pueblos que no poseen esa cualidad profunda se arriesgasen a ello, no tan sólo toparían con el instinto rezumante de conflanza de las demás naciones, sino que se quebrarían interiormente al intentar tal experiencia. No consideramos en forma alguna como pueblo supetior a la odiosa figura del advenedizo al que modelan aquéllos cuyo sentimiento de dignidad nacional tolera ser instruido, así como su nación, por un tránsfuga británico del estilo de $\mathrm{M}$. $\mathrm{H}$. St. Chamberlain, para saber lo que es "Alemania". Por otra parte, una nación que no produjese más que buenos funcionatios, oficinistas capacitados, comerciantes honrados, sabios y técnicos de gran mérito y leales servidores, y que, a fin de cuentas, se abandonase a una dominación no controlada por parte de los funcionarios con una logomaquia seudomonátquica, no sería tampoco un pueblo superior; haría mucho mejor en dedicarse a sus ocupaciones habituales en lugar de inmiscuirse con infulas en el devenir del mundo. $j$ Si tenemos que volver a nuestra antigua situación, que se nos libre al menos del lenguaje de la "política mundial"! Pues, es en vano el que los literatos inmersos en la fraseolo gía conservadora esperarán por parte de los alemanes un incremento del sentido de la dignidad en el exterior, si en el interior permanecen exclusivamente en el campo de acción de la dominación intrín. seca de los funcionarios, por muy hábil que sea ésta desde el punto de vista técnico, y si llegan hasta soportar que sabios prebendados y haítos discutan para averiguar si la nación está lo sufcientemente "madura" para tal o cual forma de gobierno.

»La voluntad de impotencia que los literatos preconizan en el in. terior del país es incompatible con la "voluntad de poder" en el exterior, que ha sido proclamada a través del mundo a bombo y platillo.' 
Si he citado este texto ${ }^{3}$ ha sido porque reúne los temas principales de la concepción weberiana de la Macbtpolitik. En el plano teórico, toda política, interior y exterior, es ante todo lucha (Kampf) entre las nacio. nes, las clases o los individuos. Unicamente los individuos impulsados por la voluntad de poder participan en esta lucha, así pues, éstos están capacitados para la política. Entre la lucha interior y la lucha exterior, jamás Max Weber ha señalado explícitamente una diferencia de naturaleza. Al igual que Maquiavelo, hallaba por doquier la lucha, pero, también al igual que aquél, sentaba la primacía de la política exterior y se marcaba como meta la unidad de su nación (en este caso la nación alemana) con el fin de que ésta estuviese en condiciones de influir sobre el curso de la historia universal. El que tan sólo un pueblo de ciudadanos y no de súbditos (Untertanen), un pueblo que se ha dado a sí mismo instituciones liberales y que participa en la lucha por el poder en lugar de sufrir con pasividad la autoridad tradicional o butocrática pueda aspirar, en tanto que Herrenvolk, a la política mundial, esa conjunción entre parlamentarismo y nacionalismo imperialista es, sin duda alguna, típica del pensamiento weberiano, pero Weber no le hubiese concedido, o en cualquier caso no bubiese debido concederle más que un valor circunstancial. En la época del capitalismo, en la Alemania wilhelminiana, dado que la autoridad patriarcal det emperador y de los junkers había quedado anacrónica o ineficaz, dado que los funcionarios, debido a su profesión, estaban desprovistos de sentido político, es decir, del sentido de lucha, Max Weber recababa la democratización o parlamentarización del régimen. Ahora bien, el que los pueblos superiores (Herrenvölker) sean siempre pueblos libres, me patece a mí que Max Weber era demasiado histotiador y demasiado pesimista para llegar a afimmatlo. También cabe la posibilidad de que la síntesis del liberalismo y del imperialismo haya respondido al criterio weberiano de los valores: la justificación del parlamentarismo debido al interés nacional, debido a los Macbtinteressen der Nation, debía conferir un carácter instrumental a preferencias espontáneamente experimentadas, $o$ quizás, más bien a violentas antipatías.

Si me atuviese al sentido amplio -el segundo-r de la Macbtpolitik, este informe deberáa, en cierta manera, abatcar el conjunto de la sociología weberiana de la política. Como no es posible acometer semejante empresa, me propongo ocuparme aquí del primer sentido del concepto de la Macbtpolitik, es decir, la política exterior, la rivalidad entre Estados que, al estar al margen de la autoridad de una ley común o de un tribunal, se

3. Politiscbe Scbriften (Escritos politicos), 1a. edición (1921), p. 269; 2a. edición (1958), p. 430. 
ven obligados a tomarse la justicia por su mano y, así pues, a depender pata sí mismos, pata su seguridad, para su existencia, de su propia fuetza y de sus alianzas. Si nos atenemos a esta defnición de la Macbipolitik, se impone de inmediato una primera observación. Max Weber, en tanto que sociólogo, no ha escrito mucho sobre la lucha entre Estados, sobre las naciones y los imperios, sobre los vínculos entre cultura y poder. El capitulo de Wirtschaft und Gesellschaft que hubiese estado dedicado a lo que se podría dar en ilamar una sociología de las relaciones internacionales ha quedado inconcluso. Si la vida le hubiese dado tiempo, Weber hubiese enriquecido probablemente esta parte, haciendo gaia de una erudición histórica sin parangón. Sin embargo, sigue existiendo un hecho incontrovertible: el nacionalismo de Weber ha sido anterior a sus investigaciones sociológicas, anterior a su obra científica; lo ha encontrado vivo en el corazón de la Alemania wilhelminiana, en el transcurso de sus años de estudio, se ha empapado de él y lo ha hecho suyo sin vacilación, al parecer sin ahondar demasiado en el tema. Bajo no pocos aspectos, Weber ha retenido la enseñanza de las famosas lecciones de Treitschke sobre la politica, aun cuando su filosofía sea más pesimista y, por así decirlo, más trágica.

De una vez para siempre, había decidido que el valor supremo al cual lo subordinaría todo, en política, el dios (o demonio) al cual había jurado fidelidad, era la grandeza de la nación alemana. Utilizo el término grandeza (Grösse), aun cuando no sea el término usado por el propio Weber, quien habla más a menudo de Macht, de Machtinteressen, de Macbtprestige y de Weltpolitik. El motivo por el cual escojo el término equívoco de grandeza es porque Weber sugiere siempre el vínculo existente entre poder y cultura. La nación alemana es un pueblo dado a la cultura (Kulturvolk). Cierto es que el poder es la meta perseguida, pero asimismo es condición de la proyección de la cultura. De cara a las generaciones venideras, Alemania, en tanto que gran potencia, es responsable del devenir de la cultura de la bumanidad.

«No son los daneses, los suizos, los holandeses, ni los noruegos a quienes las generaciones futuras, y principalmente nuestros descendientes, harán responsable si el poderío mundial -lo que, en resu* midas cuentas, viene a significar la decisión concerniente a la peculiaridad de la civilización venidera- se ve abandonado sin lucha a los reglamentos de los funcionarios rusos, por una parte, a las convenciones de la society anglosajona, por otra, con quizás un toque

4. Wirtschaft und Gesellschaft, tercera edición (1947), tercera parte, capítulo III, pp. 619 a 630 . 
de "razón" latina. Seremos nosotros a quienes harán responsables, y con razón.»"

Max Weber admitía sin vacilación ni demostración alguna la solidaridad por partida doble entre cultura y nación. «Hoy en día, toda cultura está y sigue estando sometida al fenómeno nacional, y ello tanto más que los medios exteriores se tornan más "democráticos" por lo que respecta a su difusión y a su idiosincrasia» ${ }^{6}$ entre poderío de la nación y difusión de la cultura. Ciertamente, en el capítulo inconcluso de Wirtschaft und Gesellschaft, subraya la solidaridad entre proyección y prestigio de la cultura por una parte, podetío militar y político por otra. No ilega a la conclusión de que ese poderío favorezca la calidad de la cultura. He aquí el texto tal cual figura como nota:

«El prestigio de la cultura y el del podetío van estrechamente unidos. Toda guerra victoriosa favorece el prestigio cultural (ejemplos: Alemania, Japón, etcétera). En cuanto a saber si tal hecho resulta benéfico para el desarrollo cultural, ésta es otra cuestión que ya no se puede tesolver basándose en la neutralidad axiológica. En cualquier caso, la respuesta no puede ser en manera alguna unívoca (así ocurrió con la Alemania de después del 1870), incluso basán. dose en indicios comprensibles empíricamente. $\mathrm{El}$ arte y la literatura de carácter específicamente alemán no surgieron del centro político de Alemania.»

Dos observaciones con respecto a este texto: una historia que pretendiese ser wertfrei hasta el punto de no emitir un juicio sobre la calidad de las obras resultaría sorprendentemente pobre. Llama poderosamente la atención el hecho de que al ser el poderío causa no de la calidad, sino de la difusión y del prestigio (iqueda por ver!) de la cultura, sea contempla. do por Weber como siendo la meta final.

La originalidad de Weber no estriba en la adhesión a ese nacionalismo -bastante común en las postrimerías del siglo pasado-, ni siquiera en la pasión con la cual proclamaba la necesidad de una Weltpolitik, de una política mundial en tanto que consecuencia inevitable y justificación final de la obra de Bismarck. Se me antoja original Weber, diferente de sus contemporáneos, cuando hace hincapié en el carácter diabólico del poder y en los sactificios que exige el Estado de poder. Treitschike, en sus lecciones sobre política, hallaba un algo de ridículo en los Estados pequeños. Max

5. Politiscbe Scbriften, pp. 60-61.

6. Ibid..., p. 47. 
Weber se regocija de que subsista un germanismo fuera de la Alemania convertida en un «Estado de poder nacional» (ein nationaler Machtstaat).

«Tenemos sobrados motivos -escribía el- para dar gracias al destino de que exista también una germanidad más allá de las fronteras del Estado nacional del poderío alemán. No tan sólo las humildes virtudes burguesas y la auténtica democracia, la cual aún no se ha visto realizada jamás en un gran Estado, sino además valores mucho más íntimos y sin embargo eternos no pueden florecer más que en el terreno de comunidades que renuncian al poderío político. $Y$ así sucede con un géneto tan artístico como el de un alemán tan auténtico como Gottfried Keller, quien jamás hubiese llegado a crear esa obra suya tan peculiar y única en medio del campamento militar que resulta set forzosamente nuestro Estado.» ${ }^{7}$

En lo concerniente a las relaciones entre nación y Estado, nacionalismo e imperialismo, Max Weber pertenece a su época, comparte las concepciones y también las incertidumbres de ésta. Por una parte, reconoce, subraya la fuerza de las reivindicaciones nacionales, la aspiración de todas las nacionalidades, conscientes de sí mismas, a la autonomía, incluso a la independencia. Por otra, se opone con indignación a la idea de un compromiso con Francia en lo tocante a Lorena. En cuanto a un plebiscito en Alsacia, esa idea en sí misma se le antoja tidícula. ${ }^{8}$ Max Weber no deseaba la absorción por parte del Reich de poblaciones no alemanas u hostiles. Pero, al propio tiempo, estaba muy lejos de adherirse sin reservas al principio de las nacionalidades, sea cual fuere la forma que adoptase este último. El desmembramiento de Europa central en Estados, supuestamente nacionales (pero que abarcarían inevitablemente minorías nacionales), no le parecía ni deseable ${ }^{9}$ ni realizable. Se vera inducido a concebir una política a la vez nacional e imperial, que hubiese conciliado las ansias de poder del Reich con ciertas reivindicaciones de las demás nacionalidades.

Habiendo dejado sentado que Rusia era el principal enenigo del Reich, el único que podía amenazar la existencia misma de éste, recomendó, durante la guerra de 1914-1918, una política alemana ${ }^{\text {to }}$ favorable a Polonia, menos por simpatía pata con las reivindicaciones polacas que en pro del interés nacional alemán. Estados autónomos, militarmente protegidos por el Reich, económicamente vinculados a éste, constituirían la mejor protección ante la amenaza del imperialismo ruso. No obstante $-\mathrm{y}$ en este caso

7. Ibid..., p. 60 .

8. Carta de R. Miohels, citada por Mommsen, p. 258.

9. Quizás estuviera en lo cierto.

10. Por aquel entonces había desechado por completo sus antiguas ideas de colo. nización alemana en el Este y su oposición a la afluencia de trabajadores polacos. 
también queda reflejado el espíritu de aquella época-, Max Weber no llegó sunca hasta admitir una independencia total del Estado poiaco, de igual manera que tampoco enfocaba la posibilidad de sacrificar, al Oeste, las garantías o ventajas militares a la voluntad explícita de las poblaciones.

Lo característico en Weber, con respecto a estos diferentes puntos, es la ausencia casi absoluta de justificación ideológica. Se mostraba, a mi parecer, indiferente al diálogo ideológico francoalemán con respecto a Alsacia: ¿Acaso debía prevalecer o no sobre la voluntad actual de los alsacianos el germanismo de esta provincia del imperio? De igual manera, se abstuvo de todo análisis, complejo y sutil, del "principio de las nacionalidades». Constataba la fuerza variable de los sentimientos nacionales " 1 y deducía de ellos, de forma muy realista, el peligxo de anexiones en Europa, y también la posibilidad de movilizar los sentimientos nacionales, en Europa del Este, en contra del imperio de los zares y en provecho del Reich.

Rara vez esgrimía, y lo hacía más bien implícita que explícitamente, argumentos morales o idealistas en pro de tal o cual diplomacia. Su meta fnal era arbitraria en el sentido de que nadie - ni siquiera un alemánestaba obligado a asignarse como objetivo supremo las ansias de poder del Reich. Dado que esas ansias de poder eran supuestamente inseparables de las ansias de cultura (por lo menos, del prestigio de la cultura), estaban rodeadas de una suerte de halo espiritual. Una vez realizada esta elección, el político debe en todo momento sondear lo real para determinar lo que es posible con vistas a alcaszar la meta final sin inquietarse en demasía de la moralidad o de la inmoralidad de las medidas que toma o preconiza. Si no se preocupa de ello, no es por inmoralismo, sino por honestidad intelectual. "Pues todo lo que ayuda al bien del Estado-poder se halla encadenado con las leyes del "complejo de poder" que guía toda la historia política.»"

Si esos análisis son exactos, las concepciones nacionales e imperiales de Max Weber habrían sido a la vez típicas de su época y de su generación, ${ }^{13}$ moderadas en su propósito y desprovistas de toda fraseología en cuanto a su formulación. Alemania se hallaba expuesta, ante todo, al peligro proveniente del Este, del imperio zarista o del imperialismo ruso; confió, pues, hasta la catástrofe final de 1918, en que las condiciones de paz serían tales que no excluixían una distensión de las relaciones con Gran Bretaña y Francia. Probablemente, se forjaba ilusiones sobre lo que hubiese exigido dicha distensión, pero en este caso también, si bien pecaba tal vez de falta

11. Wirtschatt und Gesellschatt, pp. 627-629.

12. Politiscbe Schriften, p. 63.

13. No creo que Max Weber haya precisado jamás to que entendía él por Weltpolitik, o tampoco cuáles hubietan sido las posesiones coloniales que hubiesen satis. fecho las ambiciones del Reich. 
de clarividencia, no es menos cierto que se mostraba más clarividente que casi todos sus contemporáneos.

Nada más fácil, peto a mi entender poco interesante, que entrat en detalles acerca de las opiniones de Weber, de seguir sus variaciones desde la famosa Antrittsrede hasta las tentativas pro polacas del tiempo de guerra. Este estudio ha sido hecho ya en numerosas ocasiones y nos apartaría de los problemas fundamentales.

Los pensadores políticos de Occidente han constatado siempre, en tanto que hecho evidente, la heterogeneidad de la política interior y de la política exterior. Cuando Hobbes, en el Leviathan, trata de plasmar el estado de naturaleza y describe las relaciones entre soberanos, presta una expresión tadical a una idea clásica. Max Weber, que define el Estado mediante el monopolio de la violencia legítima, debe, lógicamente, teconocer la heterogeneidad entre la tivalidad violenta de los Estados y la rivalidad, sometida a las leyes, de los individuos o de las clases en el seno del Estado. Sin embargo, el hecho es que Max Weber, que admitía evidentemente dicha heterogeneidad, ha atenuado más bien y enturbiado un tanto la distinción. Me parece que quedó impresionado, y en cierta medida influenciado, por la visión darviniana de la realidad social. Por ejemplo, escribía:

"Quienquieta que sea quien cobre un solo céntimo de renta que otros estén obligados a pagar - directa o indirectamente-, quien. quiera que sea quien posea un bien de consumo o utilice un medio de comunicación a costa del sudor de una frente ajena y no de su propio trabajo, éste aprovecha para su existencia los movimientos de la lucha económica por la vida, privado de todo amor e indiferente a la compasión, que la fraseología burguesa presenta como siendo un "trabajo pacífico de cultura". Ésta no es más que otta faceta de la lucha del hombre contra el hombre, en el curso de la cual no tan sólo millones sino centenares de millones de hombres se consumen cada afio en cuerpo y alma, en la que se pudren $o$, cuando menos, Ilevan una existencia de hecho infunitamente más ajena a todo "sentido" perceptible que la lucha de todos por el honor (incluidas las mujeres, pues ellas también participan en la guerta cumpliendo con su deber), lo que significa simplemente: la lucha al servicio del deber histótico que el destino ha hecho recaer sobre su pro pio pueblo.» ${ }^{14}$

Este texto está tomado de los escritos publicados en tiempo de guerra. Sin embargo, con más de veinte años de anteriotidad, en la Antrittsrede, ideas parecidas son expresadas con el mismo vigor.

14. Politiscbe Scbriften, p. 62. 
«Vemos, pues, que bajo la apariencia de la "paz" prosigue la Iucha económica entre las nacionalidades. No es en absoluto debido a un conflicto abiertamente declarado que los campesinos y los obreros alemanes del Este son expulsados de su terruño por un enemigo que sería políticamente superior a ellos; es a raíz de una rivalidad silenciosa y soterrada de cara a la vida económica de cada día que se ven aventajados por una raza menos desarrollada, que se ven obligados a abandonar sus hogares y a sumitse en un devenir incierto. Así, pues, tampoco existe paz en la lucha económica por la vida; únicamente aquel que confunde esa apariencia de paz con la verdad puede estar en la creencia de que del lejano futuro surgirán, en favor de nuestros descendientes, la paz y el goce de la vida.. ${ }^{15}$

\section{Y algo más adelante:}

«En vez del sueño de paz y de felicidad de los hombres, en el dintel de la puerta del desconocido devenir de la historia humana está escrito: lasciate ogni speranza. La cuestión que nos incita a reflexionar más allá de las tumbas de nuestra generación y que, de hecho, es el fundamento de toda labor económica, no es de saber cómo se comportarán los hombres del futuro, sino lo que será de ellos. Lo que nos gastaría cultivar no es el bienestat de los hombres, sino las cualidades con las que vinculamos el sentimiento de que constituyen la grandeza humana y la nobleza de nuestra propia naturaleza.»

\section{Y también:}

«No es la paz y la felicidad de los hombres lo que debemos proporcionar a nuestros descendientes, sino la sempiterna lucha por la conservación y la estructuración de nuestro carácter nacional. No tenemos derecho a dejarnos llevar por la esperanza optimista según la cual nuestra tarea estaría cumplida simplemente con haber conseguido el máximo desarrollo posible de la civilización económica, en tanto que la selección, merced al juego de la libre competencia económica "pacífica", contribuiría por sí misma al triunfo del tipo más desartollado.

"Nuestros descendientes nos harán responsables ante la historia no por el tipo de organización económica que les habremos legado, sino por la extensión del espacio libre que habremos conquistado para ellos y que les habremos transmitido. En último extremo, los procesos de desarrollo son asimismo luchas por el poder; ahí donde

15. Ibid..., pp. 17 y 18 . 
estén puestos en tela de juicio, los intereses de poderío de la nación son los intereses postreros y decisivos al servicio de los cuales debe ponerse la política económica. La ciencia de la política económica es una ciencia política. Es fiel servidora de la política, no de la política del momento de tal potentado o de tal clase que detenten el poder, sino de los intereses permanentes de la política en poder de la nación. Desde nuestro punto de vista, el Estado tracional no es un ente inde. terminado al que se cree realzar difuminando tanto más su razón de ser dentro de una oscuridad mística; es la organización temporal del poder. Por tanto, la razón de Estado es, para nosotros, el patrón final de los valores, incluso en la esfera de las consideraciones económicas, ${ }^{16}$

Esos textos tan a menudo citados son reveladores, a mi entender, de lo que nos vernos obligados a llamar la Weltanschatung de Max Weber, con un componente darviniano (la lucha por la vida), un componente nietscheano (no la felicidad de la humanidad, sino la grandeza del hombre), un componente económico (la escasez persistente de los bienes, la pobreza indesarraigable de los pueblos), un componente marxista " (cada clase tiene su interés, y los intereses de una clase no coinciden necesariamente con los intereses duraderos de la comunidad nacional); finalmente, un componente nacional (el interés de la comunidad nacional debe prevalecer sobre todos los demás, el nacionalismo, resultando, por otra parte, de una decisión y no de los hechos).

Hace unos treinta años, cuando leí a Max Weber pot vez primera, lo que ante todo había llamado poderosamente $\mathrm{mi}$ atención había sido la leccion de valentía intelectual y de modestia que se desprendia de su obra. $Y$ sigo creyendo que esta obra encierra aún actualmente una lección válida. Ahora bien, hoy en día, me siento asimismo sensibilizado por la metafísica, por la visión pesimista del mundo de la que se desprende ese pensamiento que quiere estar libre de toda ilusión.

La politica de poder entre las naciones, de la que las guerras son la expresión normal y una resultante inevitable, no es considerada por Max Weber como una supervivencia de tiempos ya pasados o como una negación del esfuerzo humano en pro de la cuitura, sino como una forma, entre

16. Ibid..., p. 20 .

17. En Wirtschaft und Gesellscbaft se halla otro componente marxista: la explicación del imperialistno a través de los intereses capitalistas (p. 62 y ss.). La explica. ción no es integralmente marxista en el sentido de que para Max Weber una economfa sxialista estaría tanto o más al alcance del imperialismo. Por otra parte, Weber no explica la expansión inperialista exclusivamente a través de los intereses econónicos (p. 65). 
otras formas en definitiva igualmente crueles, de la lucha por la vida o de Ia lucha entre las clases y entre las naciones. Dicho en otras palabras, una metafísica, parcialmente darviniana, parcialmente nietzscheana de la lucha por la vida, tiende a reducir el alcance de la oposición entre la paz y la guerra, entre la rivalidad económica de los pueblos y la lucha por el poder de los Estados. La violencia no deja de ser violencia pot mucho que se trate de camuflarla. Si el mismo término, Macht, designa el envite de la lucha en el seno de los Estados, y entre Estados, es que, a fin de cuentas, el envite es el mismo. Aquí y allá, de lo que se trata es de saber quién prevalece o prevalecerá, quién manda o mandará, qué parte del espacio o de los recursos disponibles conseguirá para sí cada clase o cada pueblo.

Dicha fllosofía ha quedado trasnochada por múltiples razones. Vulgarizada, interpretada por bárbaros, ha conducido a orgías de batbarie. Sin embargo, también la economía moderna ha echado por tierra no pocos criterios a los que los especialistas no titubeaban, hace medio siglo, en otorgar la dignidad de verdad científica. Max Weber, como muchos de sus contemporáneos, pero contrariamente a los economistas liberales, no parece poner en duda que el poderío político de un Estado rige el desarrollo económico de la nación. Habla y escribe como si el nivel de vida de la clase obreta dependiese únicamente de la suerte de las armas. A este respecto, Max Weber no pertenece a nuestra época. Sabemos hoy en día -y no hubiese resultado imposible saberlo bace sesenta años - que el poderío militar to es condición necesaria ni sufciente para la prosperidad material.

Que no exista aquí equívoco alguno. Max Weber había escogido el poder del Estado nacional en tanto que valor postreto, y esa elección era libre, atbitraria. Incluso si hubiese sabido que la Alemania wilhelminiana no precisaba colonias ni para el florecimiento de su cultura, ni para el bienestar de la clase obreta, no hubiese por ello cambiado su manera de pensar: las ansias de poder constituían una meta por sí mismas y sigue siendo cierto que la proyección de una cultura depende en cierta manera del poderío de la nación a la que está vinculada. Ahora bien, la imagen del mundo dejaria de ser la misma si entre las clases y entre las naciones la lucha tuviese por objetivo principal, por no decir exclusivo, el mando o el poder y no el bienestar o la propia existencia.

También es verdad que, hoy en día, corremos el riesgo de cometer, pero a la inversa, el mismo error que Weber. En el seno de las naciones lo mismo que entre las naciones, las relaciones sociales implican un elemento de conflicto al que, según los casos, se denominará competencia, rivalidad, superación. Los envites de los conflictos son múltiples, y a veces en la vanagloria de vencer reside la única recompensa. Pero, a partir del momento en que ni la existencia ni la riqueza constituyen dicho envite, en 
que la lucha es esencialmente política, es decir, que determina ante todo quién va a mandar, la distinción se torna decisiva entre las modalidades, los medios, las reglas de los diversos conflictos. Un mundo sin pugnas tesultaría, en efecto, inconcebible. En cambio, un mundo en el que las clases y las naciones no se viesen ya abocadas a la lucha por la vida (Kampf ums Desein) no es inconcebible. En cualquier caso, la diferencia entre las formas violentas y no violentas de los enfrentamientos recobra toda su importancia. El vencedor en el Wablscblacbtfeld, en el campo de la lucha electoral, difiere en cuanto a naturaleza, pero no en cuanto a importancia, del vencedor en el campo de batalla.

La visión darviniana-nietzscheana del mundo constituye un marco en el que se integra la concepción weberiana de la Macbtpolitik. El politésmo, la pluralidad de los valores incompatibles, constituye el otro fundamento fllosófico de la filosofía weberiana del poder. Max Weber, sabido es, partía de la oposición kantiana o reokantiana entre lo que es y lo que debe ser, entre los hechos y los valores. No limitaba el deber-ser a la moralidad, pero hacía de la moralidad misma un universo de valores, en medio de otros. Añadía que los universos de valores no tan sólo son independientes los unos de los otros, sino que están en conflicto irreparable. Una cosa puede ser hermosa, no aun cuando sea mala, sino porque es mala (las flores del mal). De ahi, Weber derivaba hacia dos proposiciones, tanto la una como Ia otra vinculadas a la Machtpolitik: la primera, según la cual no existe tribunal alguno que pueda estatuir acerca del valor reiativo de ia cultura alemana y de la cultura francesa; la segunda, según la cual es imposible set a la vez político y cristiano (al menos si la moral cristiana es la del Sermón de la Montaña), o también, que cada uno de nosotros, llegado el momento de actuar, debe escoger entre la moral de la convicción y la moral de la responsabilidad, y que idéntica acción, según se haya escogido una u otra ética, datá pie a una apreciación radicalmente diferente.

Arnbas proposiciones han suscitado y siguen suscitando apasionadas polémicas. La fórmula del politeísmo es, en cierta manera, evidente. El artista no es, por el mero hecho de serlo, un ser moral, y una obra de arte es hermosa, no buena. Cada universo de valores implica una finalidad espećfica, un sentido propio. La moral de los guerreros no es la misma que la de los santos o de los filósofos. Cada una de ellas sigue sus leyes. Cada nación se expresa según una determinada escala de valores, se enorgullece de determinadas obras. Entre esas escalas de valores o esas obras, ¿quién podría ser lo suficientemente objetivo y lo suficientemente justo como para poder dictaminar? Hasta aquí, todos seguimos el pensamiento de Max Weber. Más allá, empiezan a surgir interrogantes y objeciones. 
Centrémonos, en primer lugar, en el famoso texto de Wissenscbaft als Beruf (p. 545): «La imposibilidad de convertirse en el paladín de convicciones prácticas "en nombre de la ciencia" —excepción hecha del único caso que atañe a la discusión sobre los medios necesarios para alcanzar una meta prefijada- es debida a razones más profundas. Semejante actitud es, en principio, absurda dado que diferentes órdenes de valores se enfrentan en el mundo en una lucha irremediable. Sin pretender elogiar al viejo Mill, hay que reconocer, sin embargo, que no le falta razón cuando dice que si se parte de la experiencia pura se llega al politeísmo. La fórmula presenta un aspecto superficial e, incluso, paradójico y, no obstante, encierra una parte de verdad. Si hay algo que hoy en día ya no ignoramos, es que una cosa puede ser santa no solamente aun cuando no sea hermosa, sino más aún porque no lo es y en la medida que no es hermosa - se hallará referencia de ello en el capítulo 53 del Libro de Isaías y en el Salno 21. De la misma manera, una cosa puede ser bella no tan sólo aun cuando no sea buena, sino precisamente por aquello por lo que no es buena. Nietzsche nos lo ha vuelto a señalar, pero antes que él Baudelaire ya lo había dicho en Las flores del mal: éste es el título que había escogido para su obra poética. Por último, la sabiduría popular nos enseña que una cosa puede ser verdad aun cuando no sea y cuando no es ni hermosa, ni santa, ni buena. Éstos no son tnás que los casos más elementales de la lucha que enfrenta a los dioses de los diferentes ótdenes y de los diferentes valores. Ignoto cómo habría que proceder para zanjar "científicamente" la cuestión del valor de la cultura francesa comparada con la alemana; pues, ahí también diferentes dioses contienden entre sí y, probablemente, para siempre jamás. Asi, pues, las cosas no transcurren diferentemente a como transcurrían en el mundo antiguo, aún bajo el hechizo de los dioses y de los demonios, sino que toman un sesgo diferente. Los griegos ofrecian sacrificios primero a Afrodita, luego a Apolo y, sobre todo, a cada uno de los dioses de la urbe; seguimos haciendo lo mismo hoy en día, aun cuando nuestro comportamiento haya toto el encanto y se haya despojado del mito que sigue alentando a pesar de ello en nosotros. Es el destino el que gobierna a los dioses, y no una ciencia fuera ésta la que fuere.»

Cierto es que nadie puede dictaminar científicamente entre el valor de la cultura francesa y el de la cultura alemana. Ahora bien, zacaso tiene esta cuestión alguna clase de alcance? ¿Acaso resulta lícito pasar de un hecho - la cultura francesa y la alemana difieren- a la creencia de que los díoses se enfrentatán entre sí hasta la consumación de los tiempos? No puedo evitar creer que Max Weber, obsesionado por la visión de una sempiterna lucha por doquier, llega a transfigurar una rivalidad de poder, indudable peto temporal, en una lucha de dioses. Existen circunstancias en que 
las rivalidades de poder comprometen el destino mismo del hombre y del alma. No siempre es éste el caso.

¿Acaso resulta tan evidente que una cosa puede ser bella no tan sólo aun cuando, si no precisamente por aquello de que no es buena? ¿Es acaso conforme a la sabiduría de las naciones que una cosa pueda ser verdad aun cuando y en tanto que no es hermosa, ni sagrada, ni buena? La belleza de Las flores del mal tiene, aquí y allá, el mal por objeto, pero no tiene como origen una intención de maldad que hubiese podido haber animado al poeta, y si bien cabe decir que el vicio reviste, merced al poeta, las apariencias de la hermosura, no se desprende aún de ello que el vicio sea, por ese mismo hecho, la causa o la condición de la belleza. De idéntica manera, quien ve y dice la verdad, ve y dice «lo que no es ni bello, ni sagrado, ni bueno». Sin embargo, la búsqueda o la expresión de la verdad no está pot ello en conflicto intrínseco, inevitable e irremediable, con la búsqueda de la belleza, de la santidad o de la bondad.

No obstante, dejemos los conflictos de los dioses que no se tefieren más que indirectamente al tema que nos ocupa, o sea la política de poder, y lleguemos a la oposición que rige toda la filosofía de la acción de Weber, la de dos éticas de la convicción y de la responsabilidad. Nadie está obitgado, nos dice Max Weber, a adentrarse en el universo de la política; ahora bien, de bacerlo, que acepte entonces sus implacables leyes. Dado que la política tiene como envite el poder, la repartición del poder entre las clases y entre las naciones, el que aspira a guiar a sus compañeros, a los miembros de su clase o de su nación, debe someterse a las despiadadas exigencias de la lucha. Ahora bien, ésta no puede dejar de exigit medios si no malos, por lo menos peligrosos. La moral de la tesponsabilidad no se confunde, por supuesto, con la Machipolitik, y Max Weber, en un pasaje de Politik als Beruf, citado con cierta frecuencia, ha criticado el culto de la Macbtpolitik:

«Efectivatnente —escribe éf-, aun cuando, o mejor dicho, dado que el poder es el medio ineludible de la política y que, consecuentemente, el ansia de poder es una de sus fuerzas motoras, no puede existir caricatura más desastrosa de la política que la del matamoros que juega con el poder a la manera de un advenedizo, o también Narciso imbuido de su poder, en suma, todo adorador del poder en sí. Ciertamente, el simple político del poder, al que también en nuestro país se rinde un culto lieno de fervor, puede resultar efectista, pero todo se diluye en el vacio y el absurdo. Aquellos que critican ta "política de poder" tienen toda la razón del mundo a este respecto. EI repentino desmoronamiento moral de determinados representantes típicos de dicha actitud nos ha permitido ser testigos de la debilidad y 
de la impotencia que se ocultan tras aigunos gestos llenos de arrogan. cia, pero totalmente vacíos de contenido. Semejante política nunca es más que el resultado de una mente hastiada, soberanamente superficial y mediocre, cerrada a todo significado de la vida humana; por otra parte, nada más alejado de la conciencia de lo trágico, que se halla en toda acción y especialmente en la acción política, que dicha mentalidad.." ${ }^{18}$

La ética de la responsabilidad no se define por el culto al poder, ni por la indiferencia ante los valores morales, sino por la aceptación de la realidad, por la sumisión a las exigencias de la acción y, en casos extremos, por la subordinación de la salvación de su alma a la salvación de la urbe. ${ }^{19}$ En cambio, aquel que ha escogido la moral de la convicción obedece a los imperativos de su fe, fueran las que fueren las consecuencias.

De hecho, Max Weber confundía más o menos dos antinomias: por una parte, la de la acción politica con el recurso necesario a los medios, peligtosos siempre y diabólicos a veces, y la acción cristiana tal como lo sugiere el Sermón de la Montaña o las enseñanzas de san Francisco (ptesentar la otra mejilla, renunciar a todos los bienes de este mundo); por otra parte, la de la decisión sopesada, teniendo en cuenta las posibles consecuencias de la decisión, y de la elección inmediata, irrevocable, sin tomat en consideración las consecuencias posibles. Estas dos antinomias no coinciden exactamente. Ningún estadista puede ser un «cristiano puro» si es que el Sermón de la Montaña encierra lo esencial de la moral cristiana. Nadie tiene derecho a desinteresarse de las propias consecuencias de sus actos, pero nadie puede sustraerse, en determinadas circunstancias, a una exigencia interior, sean los que sean los riesgos que entraña la decisión que le dicta un imperativo categótico.

Max Webet, en tanto que teorizante, pretendía ser un moralista de la responsabilidad y aceptaba con resolución, pero también con tanta Sacblicbkeit y Nücbternheit como fuera posible, la Machtpolitik, es decir, la utilización de los medios que requiere, en el seno de las naciones como entre naciones, la lucha por el poder. Escogía la moral de Ia responsabilidad y las obligaciones de la política de poder, no por interés personal sino pot abnegación ai valor supremo al que había decidido adherirse: el poderío del Reich. Pues, el político que ansía el poder por el poder en sí, o por vanidad, o por ambición personal, no es más que una caricatura del verda. dero jefe, que no se realiza más que poniéndose al servicio de una causa superior a sus fuetzas.

18. Politische Scbriften, p. 437.

19. Ibid..., p. 477. 
Dentro de su actividad política, Max Weber no se ha comportado de manera realista, y dudo de que, a pesar de toda su ciencia y de su clarividencia, fueta llamado a convertirse en un verdadero líder. Aceptaba más fácilmente en lo abstracto y en teoría que en actos los compromisos mediocres, las componendas y las intrigas que forman parte integrante de la política efectiva, tal como se desarrolla en todos los regímenes y, especialmente, en las sociedades democráticas. Muy a menudo, Max Weber se ha mostrado más sensible, para sí y para los demás, al valor de un gesto, al significado ejemplar de una negativa que a las consecuencias previsibles de su decisión.

Max Weber tiene razón en guardarse de las ilusiones: la política corre parejas con la lucha, la lucha con la violencia, y los medios de la lucha no siempre son compatibles con la ley de Cristo o la simple moralidad. Sin embargo, hay dos extremos que me molestan en dicha teoría.

El primero es la forma extremada y en cierta manera radical dada a la antinomia entre las dos morales, la de la responsabilidad y la de la convicción. ¿Acaso resulta alguna vez posible el desinteresarse totalmente de las consecuencias de una decisión tomada? ¿Acaso resulta alguna vez posible hacer abstracción del juicio moral emitido sobre la decisión actual? El propio Max Weber, me parece a mí, lo hubiese reconocido; ahora bien, al decretar fundamental una alternativa que no se hace real más que en coyunturas extremas, corre un doble riesgo: por una parte, justificar en cierta manera a los falsos realistas que desechan con desprecio los reproches de los moralistas, por otra, a los falsos idealistas que condenan sin discriminación alguna todas las políticas por no ser conformes a sus ideales, y que acaban por contribuir, a sabiendas o no, a la destrucción del order establecido en provecho de revolucionarios ciegos o de tiranos.

Aún hay más. Max Weber hace bien en recordatnos que el eterno problema de que «el fin justifica los medios» no encierta solución teórica alguna. Ahora bien, al afirmar no tan sólo la heterogeneidad de los valores sino también su conflicto irremediable, se niega a sí mismo la posibitidad de fundar con autenticidad el sistema de valores que era el suyo. Aun cuando haya escrito que sin un mínimo de derechos del hombre no podríamos vivir, Weber ha desvalorizado sus propios valores, liberalismo y parlamentarismo, reduciéndolos a simples medios puestos al servicio de la grandeza del Reich.

$Y$ de paso, subrayo otra objeción: al sentar como meta postrera las ansias de poder de la nación alemana, eacaso no cae Max Weber en una suerte de nihilismo? El poderío de la nación, nos dice él, favorece el prestigio, no la calidad de la cultura. A partir de este momento, ¿puede el 
poderio de la nación constituir de por sí la meta final, el dios al que se le sacrifica todo? No se trata de negar la rivalidad entre naciones ni el deber de salvaguardar el lugar que oxupa la nación en el concierto mun. dial. Pero, si el poderío de la nación, sea cual sea su cultura, sean cuales sean sus gobernantes, sean cuales sean los medios puestos en uso, es el valor supremo, ¿en nombre de qué decir no a lo que el propio Max Weber hubiese rechazado con horror?

Éste es, según mi punto de vista, el extremo decisivo sobre el cual debemos teflexionar. Max Weber ha constatado y descrito la rivalidad entre las naciones europeas. Si hoy en día nos parece haber sobreestimado la importancia de dichos conflictos y subestimado las repetcusiones de una gran guerta sobre el porvenir del conjunto de las naciones europeas, Weber tiene, cuando menos con respecto a muchos de sus contemporáneos, tanto en Alemania como en Francia, la superioridad de no haber perdido el sentido de la moderación y de la decencia. Jamás ha prestado su voz a los delirios propagandísticos que imperaban en ambos bandos. No ha puesto en tela de juicio el Estado nacional, forma suprema de las comunidades políticas. (Quizás esta forma no esté aún superada en la actualidad.) Sea lo que fuere, en esto también pertenece a su época. Acerca de los derechos y deberes de las grandes potencias, acerca de las normas diplomáticas de la Macbtpolitik, se ha expresado de la misma manera que sus contemporáneos.

Lo cierto es que Max Weber, en tanto que sociólogo, es tan actual hoy como ayet, pero, en tanto que político, no siempre se ha adelantado a su época. Así es como no comprendió el alcance de la tevolución bolchevique, ni presintió el despotismo totalitario de los partidos únicos. Deseoso de preservar la democtacia de los políticos sin vocación, hacía hincapié en la legitimidad plebiscitatia del jefe carismático, mostrándose del todo in* consciente ante los peligros que debía conocer y sufrir la generación siguiente. Él, quien, mejor que cualquier otro, había comprendido la originalidad de la civilización moderna, no llegó a captar la separación, cuando menos posible, en la era de la técnica, entre el poder de las armas y la prosperidad de las naciones. Siendo antimatxista por su condición de bur. gués, esgrimió en contra de Marx bien sea la fatalidad de la burocracia, bien sea la eficacia de las creencias religiosas, pero no el hecho, común a todas las economáas modernas, del desarrollo gracias al incremento de la productividad.

Cierto es que to ha quedado aún demostrado que la visión pesimista, darviniana-nietzscheana, de Max Weber sea falsa y nuestra visión actual sea la verdadera. El futuro sigue en suspenso, e ignoramos si la humanidad decidirá destruirse o unirse. En cambio, sabemos que no teconoceremos nunca más en las ansias de poder de una nación, ni la meta postrera, ni un 
valor sagrado. Max Weber lo hizo, o crey6 hacerlo, porque la cultura acumulada a lo largo de los siglos le parecía adquirida para siempre jamás y a salvo de los altibajos de la historia. De haber sabido que en nombre del poder la propia cultura corría el riesgo de ser sacrificada, hubiese admitido que era a la vez demasiado confiado y demasiado pesimista: excesivamente confiado cuando depositaba su fe en el jefe plebiscitado y no separaba poder de cultura; excesivamente pesimista cuando no imaginaba una humanidad pacificada $o$, cuando menos, capaz de someter a reglas la lucha inevitable entte las clases y entre las naciones. En el fondo, Max Weber se ha traicionado a sí mismo en su teoría de la política, pues jamás el poder, ni el suyo ni el de la nación, ha sido su dios. Su pensamiento y su existencia se han basado en dos valores: la verdad y la nobleza. El hombre y el filósofo nos legan una herencia que los yerros del teorizante de la Machipolitik no desvirtúan. 